\title{
RESENHA DO LIVRO “TEMPO COMPRADO - A CRISE ADIADA DO CAPITALISMO DEMOCRÁTICO”, DE WOLFGANG STREECK
}

\author{
Gabriel Campos Lopes da Silva ${ }^{1}$ \\ Lorena Cabral Botelho
}

\section{CENÁRIO de PRODUÇÃo}

Wolfgang Streeck é um sociólogo econômico alemão nascido em 27 de outubro de 1946 na cidade de Lengerich. Tem como ponto central de sua pesquisa a análise política do capitalismo, escreveu ostensivamente sobre a realidade econômica e política da Alemanha. Durante os seus escritos, discursa sobre como o capitalismo pode chegar a um fim e os diversos fatores que poderiam levar isso a ocorrer, nos quais ele aborda o capitalismo como um fator contemporâneo, possuindo, assim, seu momento de crescimento, seu ápice e declínio. O autor aborda a crise atual como o ínicio de uma desordem política e econômica que levará o capitalismo democrático ao seu fim. Esse fim é devido principalmente a um avanço sistêmico do capital ao passo em que a democracia na qual ele se consolidou recua, de modo que ele já não contém a sociedade e seus anseios. Ele afirma portanto, que o capitalismo chega a um fim devido, justamente, à seu sucesso.

Ele transita com desenvoltura pelos campos da Sociologia e da Economia, resgatando conceitos de Marx quanto nas teorias da crise de legitimação de Offe e Habermas herdeiras da primeira geração da Escola de Frankfurt -, para reler a trajetória do capitalismo. É claro o seu objetivo: diante da escassez de análises atuais que explicassem as dinâmicas econômicas, busca, na base na estrutura social e de classes, desvalorizar o capitalismo de mercado, explicitando de que modo o conflito do capitalismo e da democracia se forma.

Se ao analisarmos as condições sociais, políticas e econômicas de um determinado local é possível prever crises, a bolha de 2008 que rompeu o cenário norte americano, e por este se tratar uma das maiores potências mundiais, os efeitos sentidos a nível internacional, não era esperada. A economia de mercado não previu a crise financeira imobiliária: os índices estavam estáveis, e um nova Grande Depressão parecia distante. Um alinhamento da supervalorização dos imóveis, com especulação e a não fiscalização das instituições fornecedoras de crédito possibilitou a severidade da crise de 2008. (HOLLAND, 2010).

\footnotetext{
${ }^{1}$ Graduando em Direito na Universidade Federal Fluminense (UFF)

${ }^{2}$ Graduanda em Direito na Universidade Federal Fluminense (UFF)
} 
Para o autor, existe uma incompatibilidade entre capitalismo e democracia, situada na longa transformação neoliberal do capitalismo pós-guerra a partir dos anos 1970. Nessa ideologia o mercado é perfeitamente auto-regulável, fazendo-se desnecessária a atuação do Estado, inclusive sendo mais eficiente sem este. Desde o governo Reagan, tornou-se o único caminho para os demais países - dado que as alternativas seriam formas de "socialismo social democrata" europeu, de "populismo" no Terceiro Mundo, e de "estatismo disfarçado" na Rússia e na China que seriam muito inferiores. (BRESSER-PEREIRA, 2009).

\section{RESUMO DA OBRA}

Publicado em 2012 na Alemanha, Tempo Comprado - a crise adiada do capitalismo democrático, é uma obra de Wolfgang Streeck que, seguindo as teorias da Escola de Frankfurt a respeito de crise, explora a conjuntura financeira e orçamental da Europa e de alguns outros países, como Estados Unidos e Canadá. Busca explicar, dessa maneira, a articulação econômica das potências no cenário de reestruturação dos anos 60 .

Após a Segunda Guerra Mundial, diversos Estados recorreram à políticas de "compra de tempo" para adiar, ou mesmo impedir, possíveis conflitos sociais desestabilizadores. Com o intuito de voltar a ser politicamente aceitável nas condições da concorrência de sistemas, a compra de tempo por parte do capitalismo garantiu certa lealdade das massas para com o projeto neoliberal de sociedade. De início, fez-se o uso da inflação, depois do endividamento do Estado seguido da expansão de crédito privado e, por último, da compra de dívida de Estados e de bancos pelos bancos centrais.

Essas medidas, no entanto, causaram no projeto neoliberal alguns dos efeitos antes vistos na teoria neomarxista, já que dependiam também das expectativas capitalistas de um retorno justo (just return) e resultaram em problemas de legitimação primeiramente com o capital e posteriormente com as massas. Para solucionar essa questão, o autor argumenta que será necessária "uma maior liberalização da economia política e de uma imunização da política econômica contra a pressão democrática de base, cujo objetivo é recuperar a confiança dos mercados no sistema” (STREECK, 2013)

Houve, após 1945, a imposição de regulação social ao capital, que como consequência apresentou crises - posteriores aos anos 70 no século XX-, uma vez que sempre desejou uma ordem livre de intervenções de cunho democrático. Streeck disserta a respeito da tensão existente entre o capitalismo e a democracia, na qual os problemas de legitimação do capitalismo democrático tornam-se problemas de acumulação e a economia capitalista vê-se 
cada vez mais urgente da libertação de intervenções democráticas.

O projeto neoliberal é tachado como uma fracassada estratégia político- econômica desenvolvida para enfrentar a crise. Seu sucessivo fracasso, no entanto, não precedeu o seu abandono. Para cada tentativa por parte do Estado de amenizar os sintomas da crise (e, por conseguinte, um maior aprofundamento) são criadas novas técnicas que visam a recuperação do mercado.

Contra uma política econômica keynesiana, os empregadores afirmavam que caso os empregados esquecessem da miséria associada ao desemprego na qual poderiam viver se não se submetessem à ordem do mercado, tornar-se-iam atrevidos. Chegado esse ponto, a disciplina no local de trabalho e na política poderia desmoronar. Para evitar este cenário, havia o interesse em manter um desemprego estrutural, semelhante ao modelo da teoria Marxista de exército de reserva, que, segundo Michal Kalecki, serviria para mostrar-lhe o que iria acontecer caso fossem demasiado exigentes (KALECKI, 1943). Isso pressupunha, porém, que o Estado fosse impedido de garantir pleno emprego através de instrumentos keynesianos.

Existiram então três formas de tempo comprado que podem ser analisadas de acordo com o reflexo de seus efeitos no mercado. Primeiramente, a inflação, que causou um efeito aparente de riquezas a serem distribuídas e, por conseguinte, uma "ilusão monetária" - em termos keynesianos - de um aumento da propriedade que permitia uma nova onda de consumismo, tanto para os trabalhadores quanto para os empregadores (STREECK, 2013).

O endividamento público, assim como a inflação, permite ao governo utilizar meios dos quais ainda não dispõe realmente, pois esses ainda devem ser adquiridos pelos cidadãos e recolhidos pelo Estado através de impostos. Esse endividamento acarreta a elevação das taxas de juros e demonstra uma das contradições do capitalismo, que, por um lado, defende a diminuição do Estado e o consequente alívio das contas públicas e, do outro, gera um aumento do comprometimento das verbas estatais com a reparação da dívida pública.

$\mathrm{Na}$ condição do endividamento privado, o Estado permite que os agregados familiares se endividem por sua conta e risco para compensar as perdas dos rendimentos provenientes da atividade remunerada e das prestações sociais do Estado (STREECK, 2013). Uma vez que essas medidas são adotadas, há a criação de bolhas especulativas e sucessivamente a sua explosão.

\section{CONSIDERAÇÕES FINAIS}

Na terceira parte do livro, o autor traz a lição sobre a crise entre o capitalismo e a 
democracia, mostrando a união europeia como o principal expoente moderno desse tipo de conflito que existe entre a vontade popular e o poder econômico, de uma forma geral, e em particular, a zona do euro. Neste capítulo, vemos como Streeck desenvolve a sua análise sobre a integração europeia, sua naturezas pós democráticas e neoliberais, algo que até então, só existia nas elites intelectuais, políticas e econômicas.

Trazendo as pesquisas e teses federalistas neoliberais de Friedrich Hayek, um dos pensadores de uma "democracia limitada" e de um fundamentalismo de mercado do século XX, Streeck começa por mobilizar a história das ideias, utilizando-se de um trabalho investigativo, intenso, do instituto que trata acerca do tema. Hayek, com suas teses, mostra o quanto a união europeia é uma expressão institucional que traz rigidez e uma austeridade permanente aos Estados-Nação e também as democracias, por meio de uma disciplina de mercado, suportada por instituições sem um processo democrático em sua composição, como por favor exemplo o banco central europeu, e por regras que prendem e obrigam esses estados a seguir reformas estruturais de matriz neoliberais continuadas. A "consolidação do poder" sobre as classes populares é o que faz dessa escala europeia, com suas instituições tão bem calibradas para tal consolidação, a escala política das frações mais extrovertida do capital e dos credores.

Os estados tornaram-se tão dependentes da união europeia, que já não conseguem se desvincular desta. Seja em virtude da dificuldade em conseguir a aprovação da sua população, seja pelos protocolos que devem ser seguidos até chegar a tal ponto. Ou ainda pelo receio de uma "quebra" de sua economia ao, de fato, sair do grupo. E a falta de financiamento monetário de seus bancos centrais, cria ainda mais problemas nesse âmbito, que em sua maioria são causados por uma ausência de políticas cambiais. Acabando por criar, em seus cidadãos, um sentimento de que todos possuem um destino comum com a ausência de bases materiais que compõem a soberania democrática. Quando não há uma variação cambial com a , natural, valorização ou desvalorização da moeda, cria-se um ajustamento baseado por uma “desvalorização interna" que, nada mais é do que, um processo muito mais injusto socialmente e economicamente destrutivo, já que é pautado pelas quedas dos salários diretos e indiretos (as prestações sociais).

Streeck reforça que, apesar da premissa da união europeia em ser a forma de unificar a Europa, evitando futuros conflitos ou disputas econômicas, está acaba por ser uma forma de estrangular a economia dos estados que a compõem. Ao trazer uma moeda única, as periferias e locais mais pobres, acabam por ser ainda mais prejudicadas pois como a União Europeia não é um estado, e nunca será pois os seus membros não o desejam, não há um interesse 
anti-capitalista que busque valorizar e combater a violência nessas regiões precárias.

Um outro fator identificado no texto, trata sobre as dificuldades para sair da união europeia, algo que podemos acompanhar recentemente desde o ano de 2016, com o Brexit, que invocou um referendo popular para saber se a maioria da população da grã Bretanha tinha, ou não, interesse em permanecer na união europeia. E diferente do referendo que foi invocado na década de 70, sobre o mesmo tema, agora a maioria dos cidadãos decidiu em favor da retirada de seu estado do grupo de países integrantes da união europeia. Um ato que acarretou, não somente mudanças econômicas, mas também políticas já que ao término do referendo, houve uma mudança no parlamento da grã Bretanha motivada diretamente a tal fato. E ainda que hajam dificuldades, o autor define a necessidade de desmantelar o euro para que os estados integrantes tenham de volta o suas autonomias econômicas e com isso exista, de fato, uma cooperação entre os estados, tanto em desenvolvimento econômico quanto em desenvolvimento democrático.

Concluímos então, que apesar de haverem inúmeras medidas que deveriam assegurar a soberania democrática dos países europeus, somente em integrarem a união europeia e consequentemente a zona do euro, acabam por ter parte de seus "direitos" cerceados em prol de um "bem maior". O que resta é saber quem, de fato, está se beneficiando com isso.

\section{REFERÊNCIAS BIBLIOGRÁFICAS}

EXAME: Brexit sem acordo pode paralisar economia do Reino Unido. Disponível em: $<$ https://exame.abril.com.br/economia/brexit-sem-acordo-pode-paralisar- economia-do-reinounido/> . Acesso em: 30/10/2018.

HOLLAND, Marcio. A crise de 2008 e a economia da depressão. Revista de Economia Política, São Paulo, p.30, Vol. 1, 2010.

BRESSER-PEREIRA, Luiz Carlos. Crise e recuperação da confiança. Revista de Economia Política, vol. 29, nº 1 (113), pp. 133-149, 2009. 